\title{
GLACIER ICE MASS CHANGES IN CENTRAL HIMALAYAS DURING 2000-2014 USING TanDEM- X DATA
}

\author{
D. Bandyopadhyay ${ }^{1, *}$, G.Singh ${ }^{1}$, A.V. Kulkarni ${ }^{2}$ \\ ${ }^{1}$ Center of Studies in Resources Engineering, Indian Institute of Technology Bombay, India - (gulab.singh@iitb.ac.in) \\ ${ }^{2}$ Divecha Centre for Climate Change, Indian Institute of Science, Bangalore, India - (anilkulkarni@iisc.ac.in)
}

Commission V, SS: Natural Resources Management

KEY WORDS: Glacier elevation change, TanDEM-X, SRTM, geodetic mass balance, Central Indian Himalaya

\begin{abstract}
:
The Himalayas have been widely accepted as one of the most sensitive indicators of climate change. However, the rugged terrains of the Indian Himalayas render it impossible to carry out ground based surveys in a periodic manner. Remote sensing helps bridge this gap with its synoptic coverage. Of all the available remote sensing techniques, currently synthetic aperture radar (SAR) is one of the most preferred methods owing to its all-weather and all-day imaging capacity. In this study we present, the decadal glacier mass changes in one of the catchments of the Central Himalayas in Uttarakhand using geodetic method. In this method, the prime step is the accurate estimation of change in elevation and area. For elevation changes, digital elevation models (DEMs) are required. The DEMs have been generated using high resolution TerraSAR-X/TanDEM-X scenes and standard interferometric technique. The results indicate total mass loss of $-0.05 \pm 0.01 \mathrm{Gt}$ in 2000-2014 in the Mandakini catchment. This study not only assesses the potential of the TerraSAR$\mathrm{X} / \mathrm{TanDEM}-\mathrm{X}$ dataset in glacier dynamics but also facilitates understanding the melt-water contribution of the glaciers of Indian Himalayas towards future water sustainability.
\end{abstract}

\section{INTRODUCTION}

The Indian Himalayan glaciers extend up to 40000 sq. km, featuring one of the major cryospheric components hence also known as the 'third pole' of the world (Kulkarni \& Karyakarte, 2014). Alongside, the meltwater of the glacier ice in this region has a water storage potential of approximately $3650 \mathrm{cu} . \mathrm{km}$. which supports innumerable activities like irrigation, hydropower and provides drinking water to approximately 800 million people of the country. Not only this, the glaciers act as a double-edged sword as being responsible for catastrophes like the Glacier lake outburst of floods (GLOFs). Further, the glaciers are said to be one of the most sensitive indicators of climate change. It shows its response through various parameters like retreat in areal extent, change in volume and mass loss. Hence, it is imperative that continuous monitoring be done on these glaciers.

Earlier studies on the Indian Himalayas have resulted in a plethora of information regarding the retreat of the glaciers. However, there has been evidence that glaciers particularly in the Karakoram are surging and the reason for the same is still speculative. Further, controversial statements like the likelihood of Himalayan glaciers disappearing by the year 2035 being high owing to response to climate change by the IPCC or the MOEF stating that large glaciers would take 1000 to 10,000 years to respond to climate change are merely based on intuitive studies. There is a need of using appropriate scientific tools and techniques to be able to correctly assess the present trends in glacier dynamics to develop models for future changes. To understand the effect of changing climate as well as topographic factors like slope, orientation, and debris cover, it is important to carry out studies on a long-term period. As we proceed from individual glacier scale to overall changes in a region, there is a dearth of ground information that is compensated by remote sensing data. Both the methods have an advantage. However, later has an edge having synoptic coverage and higher temporal

\footnotetext{
* Corresponding author
}

resolution, which is a huge boon as the rugged terrains of the Himalayas render it impossible to carry out field based study continuously with well distributed observation points.

Of the various glacial parameters like ice velocity, change in length or area, surface mass balance is one such parameter which responds almost simultaneously to the changes in climate (Gardelle et al., 2013). Mass changes have been estimated using various conventional methods like GPR (Ground Penetrating Radar), stake height observations or hydrological records. Despite the high reliability of these observations, the sparse distribution leads to more uncertainty as we consider the entire glacier extent. Hence, geodetic method is a useful alternative and recent studies (Gardelle $e t$ al., 2013) have proved it to be a reliable method. However, the DEMs utilized have compared C-band and optical DEMs like Cartosat, SPOT-5 or ASTER. This might lead to erroneous estimations and are also restricted to seasonal variations. On a large scale, ICESat altimetry measurements have been utilized for elevation change studies. However, these measurements are limited by spatial coverage owing to its swath. Hence, usually the observations are extrapolated which may lead to underestimation of mass change estimates. TanDEM-X dataset on the other hand, has an advantage of not being affected by weather and with near-zero temporal decorrelation and comparatively high spatial coverage as well as resolution, acts as one of the ideal dataset for such studies. This study establishes the same and estimates elevation change on a decadal scale using SRTM DEM of the year 2000 and TanDEM-X DEM for 2014.

Current studies have mainly focused on either the mass changes on a particular glacier (leading to a sparse distribution of study points for validation) or the entire Himalayan range on a coarse resolution. Catchment-wise study on such a scale has been not reported on the central Himalayan glaciers. This paper aims at providing qualitative and quantitative assessment of the mass changes taking place in terms of mass budget, reported in terms of Gt $\mathrm{yr}^{-1}$ which gives an accurate impression of the current loss of water in the form of solid ice, which fairly helps us draw a picture about the future water potential. 


\section{STUDY AREA AND DATASET}

\section{Study area}

The Mandakini basin (Figure 1) of the Garhwal Himalayas covers an area of about $1625 \mathrm{~km}^{2}$ and lies between $30^{\circ} 19^{\prime} 00^{\prime \prime} \mathrm{N}$ to $30^{\circ} 49^{\prime} 00^{\prime \prime} \mathrm{N}$ latitude and $78^{\circ} 49^{\prime} 00^{\prime \prime} \mathrm{E}$ to $79^{\circ} 21^{\prime} 13^{\prime \prime} \mathrm{E}$ longitude. This region has glaciated area as $35.65 \mathrm{~km}^{2}$ which is approximately $2 \%$ of the entire basin. Albeit the percentage, these glaciers contribute significantly to the basin catchment and further as a tributary to the Alaknanda river joining at Rudraprayag.
The Chorabari glacier is categorized as a medium sized compound valley type glacier with an area of approximately $6.6 \mathrm{sq} . \mathrm{km}$. The glacier has its accumulation area below $6578 \mathrm{~m}$ amsl (location of Bhart Kunta peak) and 6940m amsl (where the Kedarnath peak is situated) and flows from north to south with average slope of 20 degrees. This glacier has three tributary glaciers which have a steep and small accumulation area. However, the ablation area is gentle

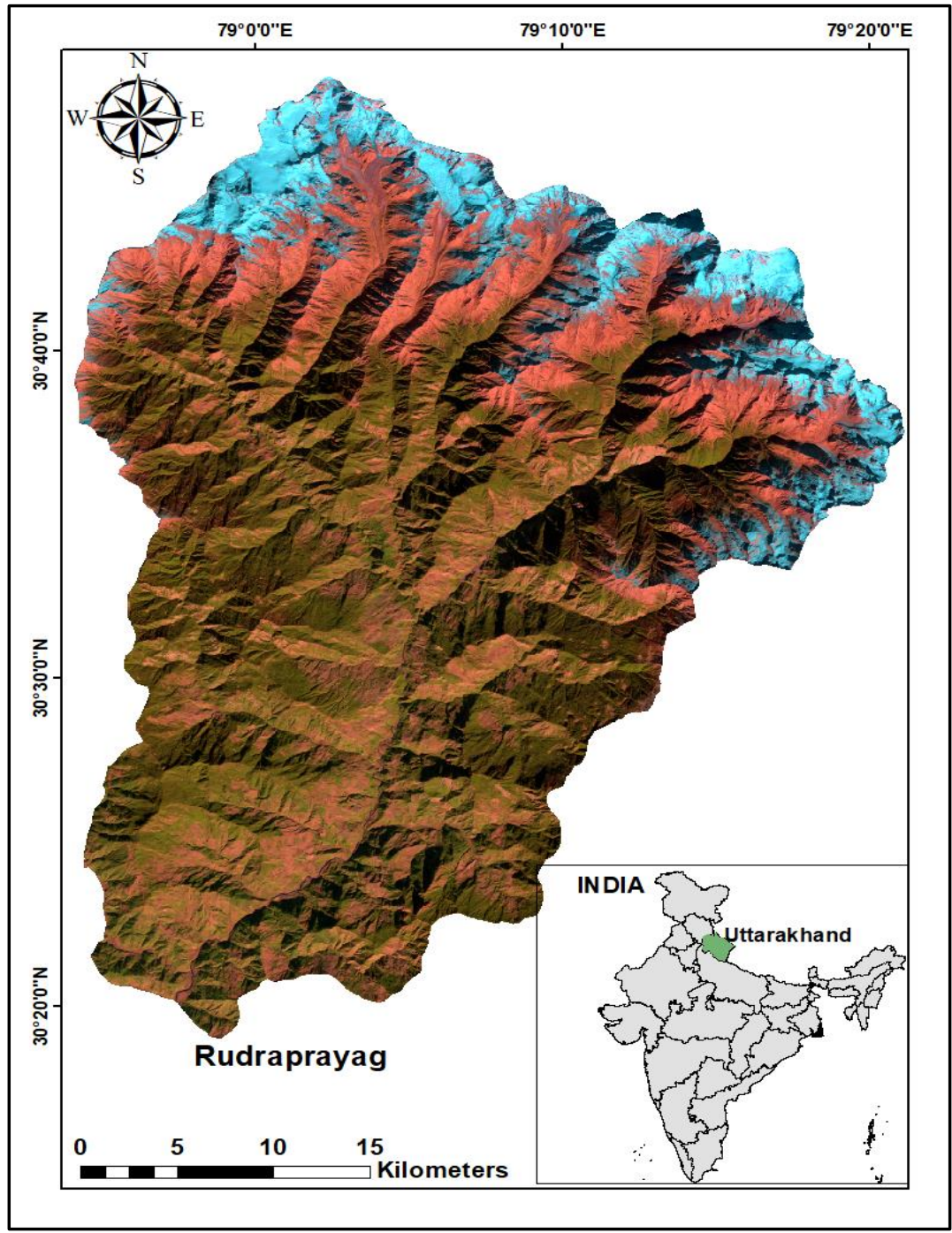

Figure 1. Location of study area using Landsat FCC image for Mandakini

The lithology of the region is mainly coarse grained mica-garnetkyanite and silimanite-bearing psammatic metamorphics. The rocks at higher Himalayas i.e. the glaciated region consists of these rocks forming U-shaped valley glacier. The meteorological data indicates that the area is mainly summer monsoon fed with little contribution from the western disturbances during winter (Mehta $e t$ al., 2012).

The importance of this study is in reference to the Chorabari glacier which acts as a source for the Mandakini River, which eventually joins the Alaknanda River (a tributary of River Ganga) at Rudraprayag in Uttarakhand, India. This glacier thus, serves as a source of freshwater reserve for population downstream. Also, in 2013, an unprecedented outburst of the Chorabari Lake, led to the mass destruction of life and property, hence an important glacier for in-depth study. and covered in thick debris, as thick as $50 \mathrm{~cm}$. In fact, this glacier has $80 \%$ of its ablation area covered in debris.

\section{Dataset}

The SRTM DEMs are available in both X- and C- band. The SRTM mission launched in 2000 was jointly carried out by NASA and DLR, providing global coverage using simultaneously operating Xband and C-band systems.

Due to limited coverage of the $\mathrm{X}$ - band data over the glaciated region, elevation change studies have been carried using SRTM-C and TanDEM-X DEM. However, the penetration bias of C- and Xband have been estimated using the SRTM dataset. The advantage of using TanDEM-X data is that the TanDEM-X mission with its twin satellite flying in helix-formation records backscatter with negligible time lag due to which there is near-zero temporal decorrelation (Krieger et al., 2007), which is generally a trivial 
problem for dataset used in the interferometric technique for DEM generation.

The glacier outlines have been used from the Randolph Glacier Inventory (RGI) database, which were created between 2001 and 2011. Since, the study period is from 2000-2014, the glacier outlines are manually corrected wherever necessary using Landsat imagery of the same time-period.

\begin{tabular}{|c|c|c|c|}
\hline Dataset & Year & $\begin{array}{c}\text { Resolution } \\
(\mathbf{m})\end{array}$ & $\begin{array}{c}\text { Vertical } \\
\text { Accuracy (m) }\end{array}$ \\
\hline SRTM (C-band) & 2000 & 30 & 15 \\
SRTM (X-band) & 2000 & 23.5 & 15 \\
TanDEM-X & $2011-$ & 12 & 2 \\
Landsat & 2014 & 30 & - \\
\hline
\end{tabular}

Table 1. Dataset specifications

\section{METHODOLOGY}

The methodology followed for current study is as follows:

- Generation of TanDEM-X DEMs using the standard interferometric technique with SRTM DEM as reference. This is followed by DEM differencing. However, bias correction is an important step before the two DEMs i.e. SRTM and TanDEM-X are utilized for extraction of decadal elevation change.

- The bias correction is done using SRTM-X and C- band for both on and off-glacier regions. This bias is incorporated in the elevation change estimated. Before calculating the elevation change, since the two DEMs are of different projection, spatial resolution and have been processed using different GCPs, appropriate pre-processing is required for comparing the two DEMs.

- Following elevation change, volume change is calculated using the glacier boundary provided by the RGI inventory (6.0). Finally, the mass change conversion is performed by multiplying with an approximated density of $850 \pm 60 \mathrm{~kg} \mathrm{~m}^{-3}$ (Huss, 2013).

- The accuracy assessment is performed using the standard method of normalized median absolute deviation (NMAD). This method is preferred as it is robust for even outliers, which is generally the case while studying glaciated terrains.

\section{RESULTS AND DISCUSSION}

For elevation change, the DEM differencing method was applied and the mean elevation change in the Mandakini basin has been found to be $-6.78 \pm 0.13 \mathrm{~m}$ over the time period, 2000-2014. This range estimate incorporates the DEM accuracy.

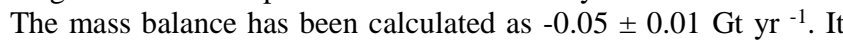
may be noted that the mass balance estimated might seem to be significantly less contributory to the overall stream flow of the Alaknanda or the Ganges, however, it must be understood that it was the bursting of the Chorabari lake (downstream of Chorabari glacier) owing to excess melt and unprecedented precipitation, that played havoc for the people living downstream. Till date, rehabilitation in full capacity has not been achieved.

To validate our results we performed the same study on Chorabari glacier, one of the benchmark glaciers of the Central Himalayan region. Here the red color signifies maximum elevation change in the range of -15 to $-10 \mathrm{~m}$ and the cyan color represents increase in ice/snow thickness. The Chorabari glacier shows a marked decrease in thickness in the accumulation zone (as seen in Figure 3.). This could be attributed to the presence of high debris cover in the ablation zone, which leads to a comparatively low melting rate. The thin layer of debris cover and steep slope could be the reason for the rather high glacier ice/snow/firn melt in the accumulation zone. Our specific mass balance observations compare with the estimates in Bandyopadhyay et al., 2018, however comparative analysis with mass balance records using glaciological measurements differ. The reason could be the sparse point observations which have been averaged over the entire glacier as well the difference in the time period.

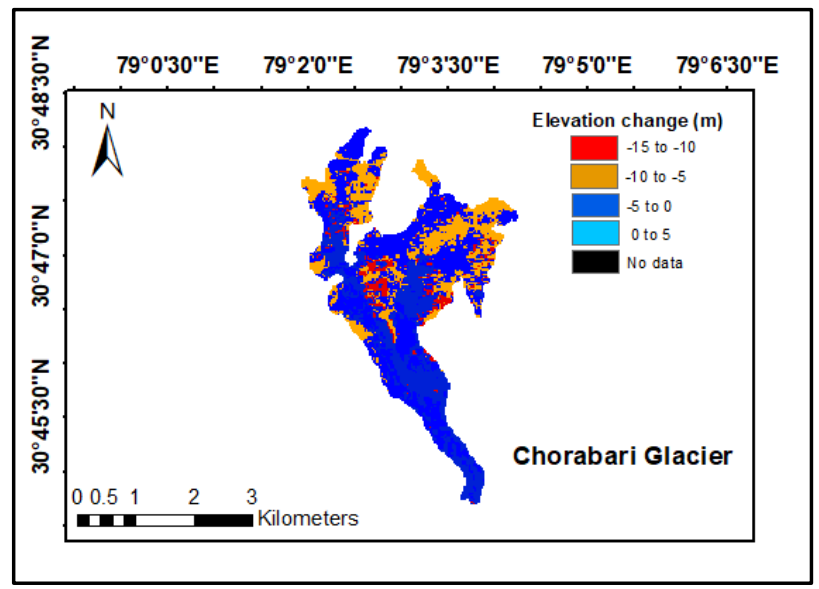

Figure 3. Elevation change for Chorabari glacier from 2000-2014

The glacier melt can be influenced by a number of topographic factors as well as climatic factors. However, within the same basin topography plays a major role. The topographic parameters include slope, orientation, debris cover, presence of glacial lakes, altitude, location, size of glacier as well as surge activity. In this study the effect of size and location do not play an active role in deciding the glacier melt rate owing to the similarity in the range of size of glaciers as well as location. The effect of debris has been observed in individual glacier scale. Further, this region does not show any surging activities which could alter the trend of current glacier melt.

\section{CONCLUSION}

In this study, potential of high resolution TerraSAR-X/TanDEM-X DEMs has been explored over the selected area of study for elevation change studies. This input is crucial when considering mass balance of glaciers. Mass balance calculations suggest that the glaciers of Mandakini basin are retreating both in overall areal extent as well as elevation. It is recommended that these results be corroborated with other techniques and dataset, which will be carried out as a part of future work. For debris covered glaciers, which is a common feature in the Central Himalayan region, incorporating analysis from various energy-balance models/observations would act as a valuable input. To understand the relation of climate change with the glacier melt, a plausible solution would be to incorporate the various climate parameters as well. This would help quantify the role of these parameters in the dynamics of the glaciers.

With the IPCC recognizing the Himalayan glaciers as one of the key indicators of regional climate change, SAR interferometric technique would prove to be a useful alternate technique wherein the issues like cloud cover in tropical countries like India constrain continuous monitoring of glaciers. Hereafter, it is suggested that SAR-fusion techniques are a way forward for understanding the glacier dynamics better. 


\section{ACKNOWLEDGEMENTS}

The authors acknowledge the support of the Ministry of Human Resource Development under IMPRINT scheme with project no 4096. The authors would also like to thank German aerospace Center DLR project DEM_GLAC1805 and DEM_GLAC1788 for kindly providing TanDEM-X global DEMs as well as thank USGS for Landsat data and SRTM-C data which was made freely available.

\section{REFERENCES}

Bandyopadhyay, D., Singh, G., Birajdar, F., 2018. Remote sensing analysis of changes in Chorabari glacier , Central Himalaya , India. Current Science 114, 771-775. https://doi.org/10.18520/cs/v114/i04/771-775

Dobhal, D.P., Mehta, M., Srivastava, D., 2013. Influence of debris cover on terminus retreat and mass changes of Chorabari Glacier, Garhwal region, central Himalaya, India. Journal of Glaciology 59, 961-971. https://doi.org/10.3189/2013JoG12J180

Gardelle, J., Berthier, E., Arnaud, Y., Kääb, A., 2013. Regionwide glacier mass balances over the Pamir-Karakoram-Himalaya during 1999\&ndash;2011. The Cryosphere 7, 1263-1286. https://doi.org/10.5194/tc-7-1263-2013

Huss, M., 2013. Density assumptions for converting geodetic glacier volume change to mass change. The Cryosphere 7, 877887. https://doi.org/DOI 10.5194/tc-7-877-2013

Kääb, A., Berthier, E., Nuth, C., Gardelle, J., Arnaud, Y., 2012. Contrasting patterns of early twenty-first-century glacier mass change in the Himalayas. Nature 488, 495-498. https://doi.org/10.1038/nature11324

Krieger, G., Moreira, A., Fiedler, H., Hajnsek, I., Werner, M., Younis, M., Zink, M., 2007. TanDEM-X: A satellite formation for high-resolution SAR interferometry. IEEE Transactions on Geoscience and Remote Sensing 45, 3317-3340. https://doi.org/10.1109/TGRS.2007.900693

Kulkarni, A. V., Karyakarte, Y., 2014. Observed changes in Himalayan glaciers. Current Science 106, 237-244.

Mehta, M., Majeed, Z., Dobhal, D.P., Srivastava, P., 2012. Geomorphological evidences of post-LGM glacial advancements in the Himalaya: A study from Chorabari Glacier, Garhwal Himalaya, India. Journal of Earth System Science 121, 149-163. https://doi.org/10.1007/s12040-012-0155-0

Pratap, B., Dobhal, D.P., Bhambri, R., Mehta, M., Tewari, V.C., 2016. Four decades of glacier mass balance observations in the Indian Himalaya. Regional Environmental Change 16, 643-658. https://doi.org/10.1007/s10113-015-0791-4 